\title{
Naringin induces autophagy-mediated growth inhibition by downregulating the PI3K/Akt/mTOR cascade via activation of MAPK pathways in AGS cancer cells
}

\author{
SUCHISMITA RAHA ${ }^{1}$, SILVIA YUMNAM ${ }^{1}$, GYEONG EUN HONG $^{1}$, HO JEONG LEE ${ }^{1}$, \\ VENU VENKATARAME GOWDA SARALAMMA ${ }^{1}$, HYEON-SOO PARK ${ }^{1}$, JEONG DOO HEO ${ }^{2}$, \\ SANG JOON LEE ${ }^{2}$, EUN HEE KIM ${ }^{3}$, JIN-A KIM ${ }^{4}$ and GON SUP KIM ${ }^{1}$
}

\begin{abstract}
${ }^{1}$ Research Institute of Life Science and College of Veterinary Medicine (BK21 plus project), Gyeongsang National University, Gazwa, Jinju 660-701; ${ }^{2}$ Gyeongnam Department of Environmental Toxicology and Chemistry, Toxicology Screening Research Center, Korea Institute of Toxicology, Jinju 666-844; Departments of ${ }^{3}$ Nursing Science and

${ }^{4}$ Physical Therapy, International University of Korea, Moonsan, Jinju 660-759, Republic of Korea
\end{abstract}

Received June 3, 2015; Accepted June 26, 2015

DOI: 10.3892/ijo.2015.3095

\begin{abstract}
Naringin, one of the major bioflavonoid of Citrus, has been demonstrated as potential anticancer agent. However, the underlying anticancer mechanism still needs to be explored further. This study investigated the inhibitory effect of Naringin on human AGS cancer cells. AGS cell proliferation was inhibited by Naringin in a dose- and time-dependent manner. Naringin did not induce apoptotic cell death, determined by no DNA fragmentation and the reduced Bax/ Bcl-xL ratio. Growth inhibitory role of Naringin was observed by western blot analysis demonstrating downregulation of $\mathrm{PI} 3 \mathrm{~K} / \mathrm{Akt} / \mathrm{mTOR}$ cascade with an upregulated $\mathrm{p} 21^{\mathrm{CIPI} / \mathrm{WAFI}}$. Formation of cytoplasmic vacuoles and autophagosomes were observed in Naringin-treated AGS cells, further confirmed by the activation of autophagic proteins Beclin 1 and LC3B with a significant phosphorylation of mitogen activated protein kinases (MAPKs). Collectively, our observed results determined that anti-proliferative activity of Naringin in AGS cancer cells is due to suppression of PI3K/Akt/mTOR cascade via induction of autophagy with activated MAPKs. Thus, the present finding suggests that Naringin induced autophagymediated growth inhibition shows potential as an alternative therapeutic agent for human gastric carcinoma.
\end{abstract}

Correspondence to: Professor Gon Sup Kim, Research Institute of Life Science and College of Veterinary Medicine, Gyeongsang National University, 900 Gajwa-dong, Jinju, Gyeongnam 660-701, Republic of Korea

E-mail: gonskim@gnu.ac.kr

Key words: naringin, gastric carcinoma, AGS cells, growth inhibition, autophagy, MAPKs

\section{Introduction}

Gastric cancer remains highly prevalent and accounts for a notable proportion of global cancer mortality, with poor survival rates (1). According to GLOBOCAN estimation for $2015,1034,124$ new cases of gastric cancer are predicted to be diagnosed, accounting for 785,558 new deaths annually (2). It is the third leading cause of cancer-related death $(>8 \%$ of the total) and fifth most common malignancy in both sexes worldwide. The case-fatality ratio is higher than the common malignancies such as lung, colon, breast, and prostate cancers (3) with 70\% cases in developing countries where, $50 \%$ accounts for only in Eastern Asia (4). Despite advancement in the current diagnosis and major therapies including surgery and chemotherapy, it carries a poor prognosis due to non-specific symptoms in early stages with 5-year relative survival $<20 \%$ in most countries (5). Due to its multidrug resistance to classical chemotherapies, potent bio-therapeutic targets are now required as alternative preventive methods.

It is well known that sustaining proliferative signals and resisting cell death are crucial hallmarks of cancer cells (6). In addition it possesses the capability to regulate cancer cell development and progression by downregulating the growthstimulatory signals, upon activation of tumor suppressor genes. PI3K/Akt (protein kinase B)/mTOR (mammalian target of rapamycin) cascade is probably the most frequently altered signaling pathway in cancer (7). These serine/theorine proteins are regarded as important key regulators of many essential cellular processes including cell survival, proliferation, growth, and differentiation (8). The activation of PI3K/ Akt stimulates mTOR, which allows cells to inhibit autophagic progression followed by cell death (9).

Autophagy is a ubiquitous physiological process in all eukaryotic cells. The most prevalent form of autophagy known as 'macro-autophagy', has been defined as type II programmed cell death (PCD) (9). Autophagy begins with the formation of double-membrane vesicles known as autophagosomes that 
engulf cytoplasmic constituents including organelles followed by maturation process upon fusion with lysosomes and finally become autolysosomes, which undergoes a cellular degradation process lead by lysosomal enzyme in response to starvation and stress (10). Several studies have reported that autophagy promotes cancer cell death in response to various anticancer agents on apoptosis defective cell (11-14). Accordingly, overactivation of autophagy in cancer cell has been proposed to play an important death mechanism during tumor progression, where apoptosis is limited (15).

MAPK signaling has been implicated in numerous cellular responses including inflammation, cell cycle, cell death, development, differentiation, tumorigenesis and senescence (16). Numerous studies have shed light on activation of MAPKs including extracellular signal-regulated kinase (ERK1/2), c-Jun $\mathrm{N}$-terminal kinase (JNK) and p38 MAPKs induced autophagy in cancer cells $(17,18)$, subsequently accompanied by an increase of autophagy regulatory protein and tumor suppressor genes (19). Furthermore, induction of autophagic cell death in cancer cell could be triggered by $\mathrm{p} 21^{\mathrm{WAF} 1 / \mathrm{CIP} 1}$, popularly known as a potent master effector of multiple tumor suppressor pathway promoting anti-proliferative activities (20-22).

The use of herbal medicine and supplements increased tremendously over the past three decades with people worldwide gaining health benefits (23). Over last few years, several investigations established dietary substances from fruits, vegetables, tea and wine with health promoting activities. Citrus fruits have been widely studied for their therapeutic role in human cancer $(24,25)$ as they contain a great variety of phytochemicals such as flavonoids, limonoids, phenolic acid and ascorbic acid. Flavonoids are a large group of heterogeneous polyphenols carrying potential anti-carcinogenic and antitumor activities. Naringin, a major flavonoid mostly available in grape and citrus fruits, exerting a variety of pharmacological effects such as antitumor (26), antioxidant (27), cholesterol-lowering, anti-atherogenic (28), anti-inflammatory (29), antiviral and inhibitory activities followed by induction of apoptosis in different cancer cells have been reported $(30,31)$. However, Naringin exhibiting growth regulatory mechanism relevant to non-apoptotic cell death signaling pathways in cancer cells is still unidentified.

Therefore, the present study evaluated the inhibitory mechanism of flavonoid Naringin in AGS human cancer cell, presenting a detailed observation on induction of autophagy by downregulating PI3K/Akt/mTOR signaling cascade via activation of MAPK families. This report unveils that Naringin induced autophagic growth inhibition in human AGS gastric cancer cells.

\section{Materials and methods}

Chemical and reagents. Roswell Park Memorial Institute (RPMI)-1640 medium was purchased from Hyclone (Logan, UT, USA). Fetal bovine serum (FBS) and antibiotics (streptomycin/penicillin) were obtained from Gibco (BRL Life Technologies, Grand Island, NY, USA). 3-(4,5-dimethylthiazol-2- yl)-2,5-diphenyltetrazolium bromide (MTT) and Naringin (Fig. 1A) were purchased from Sigma-Aldrich (St. Louis, MO, USA). Materials and chemicals used for electrophoresis were obtained from Bio-Rad (Hercules, CA,
USA). Primary antibodies ERK1/2, p-ERK1/2 $\left(\mathrm{Thr}^{202} / \mathrm{Tyr}^{204}\right)$, JNK, p-JNK (Thr ${ }^{183} /$ tyr $\left.^{185}\right)$, p38, p-p38 $\left(\right.$ Thr $\left.^{180} / \operatorname{Try}^{182}\right)$, p-PI3K $\left(\mathrm{Tyr}^{458} / \mathrm{Tyr}^{199}\right)$, p-Akt $\left(\operatorname{Ser}^{473}\right)$, mTOR, p-mTOR $\left(\operatorname{Ser}^{2448}\right)$, LC3B, Beclin 1, Bcl-xL and PI3K inhibitor LY294002 were purchased from Cell Signaling (Beverly, MA, USA). Akt (H-136) and Bax (P-19) were purchased from Santa Cruz Biotechnology, Inc. (Santa Cruz, CA, USA). PI3K p110 $\delta$ antibody was obtained from Enzo Life Sciences. Anti-p21 ${ }^{\mathrm{WAF} 1 / \mathrm{CIP} 1}$ and $\beta$-actin were purchased from Millipore (Billerica, MA, USA). Anti-rabbit IgG horseradish conjugate secondary antibody was purchased from Enzo Life Sciences. All the chemicals used were of the highest grade commercially available.

Cell culture and treatment. AGS cancer cell line, which is a gastric adenocarcinoma, was obtained from the Korean Cell Line Bank (Seoul, Korea). AGS cells were maintained in RPMI-1640 supplemented with $10 \%$ heat inactivated FBS and $1 \%$ penicillin/streptomycin at $37^{\circ} \mathrm{C}$ in a $5 \% \mathrm{CO}_{2}$ incubator. Cells were treated with vehicle alone (DMSO) or a series of concentrations of Naringin dissolved in 1\% DMSO.

Cell proliferation activity. Cell proliferation of AGS cancer cells was assessed using MTT. Cells were seeded at density of $2.5 \times 10^{4}$ cells per well in a 24 -well plate, incubated overnight at $37^{\circ} \mathrm{C}$ in a $5 \% \mathrm{CO}_{2}$ incubator and treated with various concentrations of Naringin (1, 2 and $3 \mathrm{mM}$ ) or vehicle alone (DMSO) for 24 and $48 \mathrm{~h}$. After treatment, MTT solution $(5 \mathrm{mg} / \mathrm{ml}$ in 1X PBS) was added followed by incubation for $3 \mathrm{~h}$ at $37^{\circ} \mathrm{C}$ in the dark. The formazan crystals formed were solubilized by incubating cells with $500 \mu \mathrm{l}$ of DMSO. Cell absorbance was read by enzyme-linked immunosorbent assay (ELISA) plate reader (BioTek Instruments Co., Korea) at $540 \mathrm{~nm}$. Cell proliferation was quantified as a percentage compared to the control group (untreated cells), which was set at $100 \%$.

DNA fragmentation assay. DNA was isolated with little modification following DNA extraction protocol (32). Briefly, untreated and Naringin-treated cells incubated for $24 \mathrm{~h}$ were harvested and were lysed with cell lysis buffer for $30 \mathrm{sec}$ at room temperature (RT). The supernatant was collected after centrifugation at 3,000 rpm for $5 \mathrm{~min}$ followed by incubation at $56^{\circ} \mathrm{C}$ for $2 \mathrm{~h}$ after adding $10 \%$ SDS solution and RNase A. Proteinase K $25 \mathrm{mg} / \mathrm{ml}$ was added and incubated overnight till complete lysis at $37^{\circ} \mathrm{C}$. After adding saturated $\mathrm{NaCl}$ and absolute ethanol to the samples, the mixture was incubated at $-80^{\circ} \mathrm{C}$ for precipitation. Centrifuging for $20 \mathrm{~min}$ at $12,000 \mathrm{rpm}$ followed by washing the white pellet with $80 \%$ ice cold ethanol and air-dried at RT. The obtained pellets were dissolved in 1X TE buffer. The total DNA solutions were then subjected to $1.5 \%$ agarose gel electrophoresis at $100 \mathrm{~V}$ for $45 \mathrm{~min}$ at room temperature. Tris acetate EDTA was used as the electrophoresis running buffer and DNA bands were visualized by UV light and documented by photography.

Electron microscopy analysis. For the transmission electron microscopy analysis (TEM) the cells were seeded in a $100-\mathrm{mm}$ dish and incubated with vehicle or $2 \mathrm{mM}$ Naringin for $24 \mathrm{~h}$. The cells were harvested and fixed in $4 \%$ formaldehyde and $1 \%$ glutaraldehyde phosphate buffer $(1: 1)$ for $48 \mathrm{~h}$ at $4^{\circ} \mathrm{C}$. The fixative was pipetted and replaced with $8 \%$ sucrose in $1 \mathrm{X}$ PBS, 
A

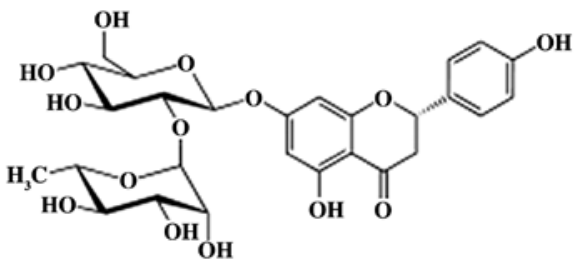

B

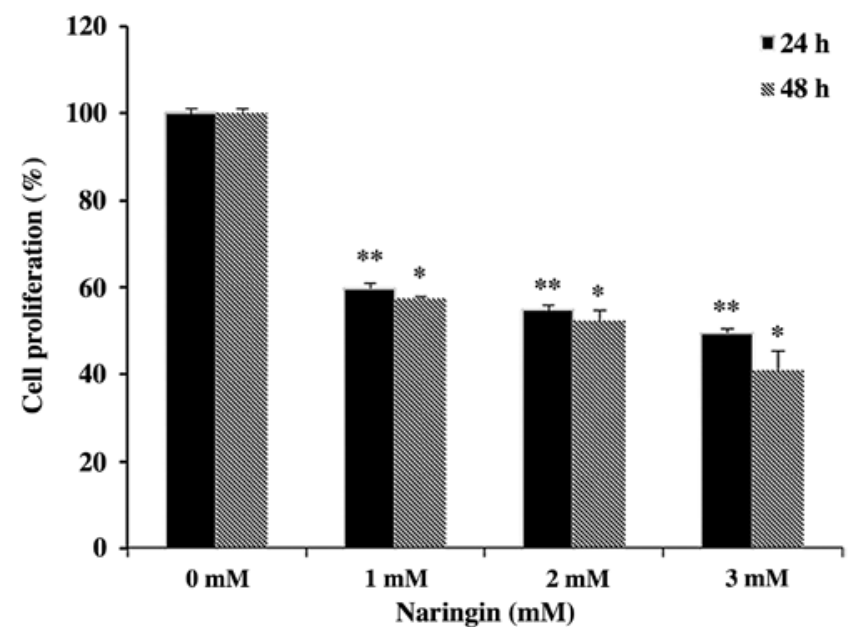

Figure 1. Inhibitory effect of Naringin on AGS cell proliferation. (A) Chemical structure of Naringin. (B) AGS cells were treated with series concentrations of Naringin for 24 and $48 \mathrm{~h}$. The cell viability was measured by MTT assay, and the data are presented as means $\pm \mathrm{SD}$ of three replicated independent experiments. ${ }^{*} \mathrm{p}<0.05$ and ${ }^{* *} \mathrm{p}<0.01$ compared with control group.

followed by post-fixation with $1 \%$ osmium tetraoxide for $1 \mathrm{~h}$ at $4^{\circ} \mathrm{C}$. The cells were then washed with $1 \mathrm{X}$ PBS three times for 10 min. After dehydration in 50-100\% ethanol, the cells were embedded in Poly/Bed 812 resin (Pelco, Redding, CA, USA). The cells were polymerized overnight at $60^{\circ} \mathrm{C}$. Ultrathin sections were stained with lead citrate and examined on Tecnai 12, FEI transmission electron microscope.

Western blot analysis. Briefly, AGS cells treated with $1 \mathrm{mM}$ and $2 \mathrm{mM}$ Naringin or vehicle (as control) for $24 \mathrm{~h}$ were lysed overnight with lysis buffer (RIPA) containing phosphatase inhibitor cocktail along with protease inhibitor and EDTA (Thermo Scientific, MA, USA). The extracted proteins were then centrifuged at $14000 \mathrm{rpm}$ for $30 \mathrm{~min}$ at $4^{\circ} \mathrm{C}$ to remove debris. The proteins were resolved using 8-15\% SDS-PAGE and subsequently transferred to polyvinylidene difluoride (PVDF) membrane (Immunobilon-P, $0.45 \mathrm{~mm}$; Millipore) using the TE 77 Semi-Dry Transfer Unit (GE Healthcare Life Sciences, Buckinghamshire, UK). The membranes were blocked with $5 \%$ non-fat milk in Tris-buffered saline containing 1\% Tween-20 (TBS-T, pH 7.4) or $1 \mathrm{X}$ phosphoblocking solution (TransLab, Biosciences in Korea) at RT for $1 \mathrm{~h}$. Blots were probed with a 1:500 or 1:1,000 dilutions of the respective primary antibodies at $4^{\circ} \mathrm{C}$ overnight. After washing five times with TBS-T, the membranes were incubated with a 1:1,000 diluted enzyme-linked secondary antibodies at RT for $3 \mathrm{~h}$. The immune blots were visualized using an enhanced chemiluminescence (ECL) kit and Western Blotting Detection Reagents (GE Healthcare Life Sciences). Each protein band was quantified using ImageJ software (http://rsb.info.nih.gov) followed by densitometry reading, undertaken after normalization by $\beta$-actin expression.

Inhibitor assay. To explore the effect of PI3K as upstream targets of PI3K/Akt/mTOR signaling pathway on Naringin induced autophagy in AGS cell growth inhibition, $10 \mu \mathrm{mol} /$ LY294002 (a PI3K specific inhibitor) were pre-treated for $2 \mathrm{~h}$ prior to the addition of $2 \mathrm{mM}$ Naringin followed by 24-h incubation. The protein expression was analyzed by immunoblotting as described above against the p-PI3K and LC3B antibodies.

Statistical analysis. The obtained results were expressed as the mean \pm standard deviation (SD) of a minimum three replicates in independent experiments. The data were analyzed by unpaired, two tailed Student's t-test using SPSS version 10.0 for Windows (SPSS, Chicago, IL, USA). The p-value of $<0.05$ and $<0.01$ was considered statistically significant.

\section{Results}

Effect of Naringin on AGS cell proliferation. In order to assess the potential anti-proliferative activity of Naringin on AGS cancer cells, MTT assay was conducted. The anti-proliferative effect of Naringin on AGS cancer cells were examined doseand time-dependently. It has been observed that treatment with different doses of Naringin (0-3 mM) or vehicle alone at two time points (24 and $48 \mathrm{~h}$ ) exhibited significantly decreased cell proliferation (Fig. 1B). Besides, $>50 \%$ cell growth inhibition was observed at $3 \mathrm{mM}$ dose within 24-h, but the opted effective concentration (EC) of Naringin was $2 \mathrm{mM}$ based on the morphological observation of treated AGS cells with visible increased vacuolization. Moreover, the cell growth was efficiently attenuated dose- and time-dependently followed by $59.8,54.8$ and $49.5 \%$ in $24 \mathrm{~h}$ and $57.4,52.5$ and $41.02 \%$ in $48-\mathrm{h}$ durations respectively at subsequent doses of Naringin.

Naringin attenuates AGS cancer cell growth: non apoptotic cell death. DNA fragmentation has been considered as hallmark for apoptotic cell death which proceeds before the onset of morphological changes during apoptosis. On the contrary, Naringin attenuated AGS cell growth, investigation was conducted to confirm the induction of apoptotic cell death by $1.5 \%$ agarose gel electrophoresis analysis. DNA ladder assay presented no apparent DNA inter-nucleosomal fragmentation in the $2 \mathrm{mM}$ Naringin-treated AGS cells for $24 \mathrm{~h}$ compared with control (Fig. 2A), suggesting the cell death occurrence was not due to apoptosis. Further confirmation was done to observe the potential role of apoptosis related proteins in Naringin-treated cells. Western blot analysis for $\mathrm{Bax}$ and $\mathrm{Bcl}-\mathrm{xL}$ (Bax/Bcl-xL) relative ratio revealed a gradual decreasing trend in Naringin-treated AGS cells (Fig. 2B). Thus, collectively these results supported non-apoptotic cell death in the Naringin-treated AGS cell line.

Naringin downregulates the expression of PI3K/Akt/mTOR cascades. In human cancer cells, activated Akt and mTOR 

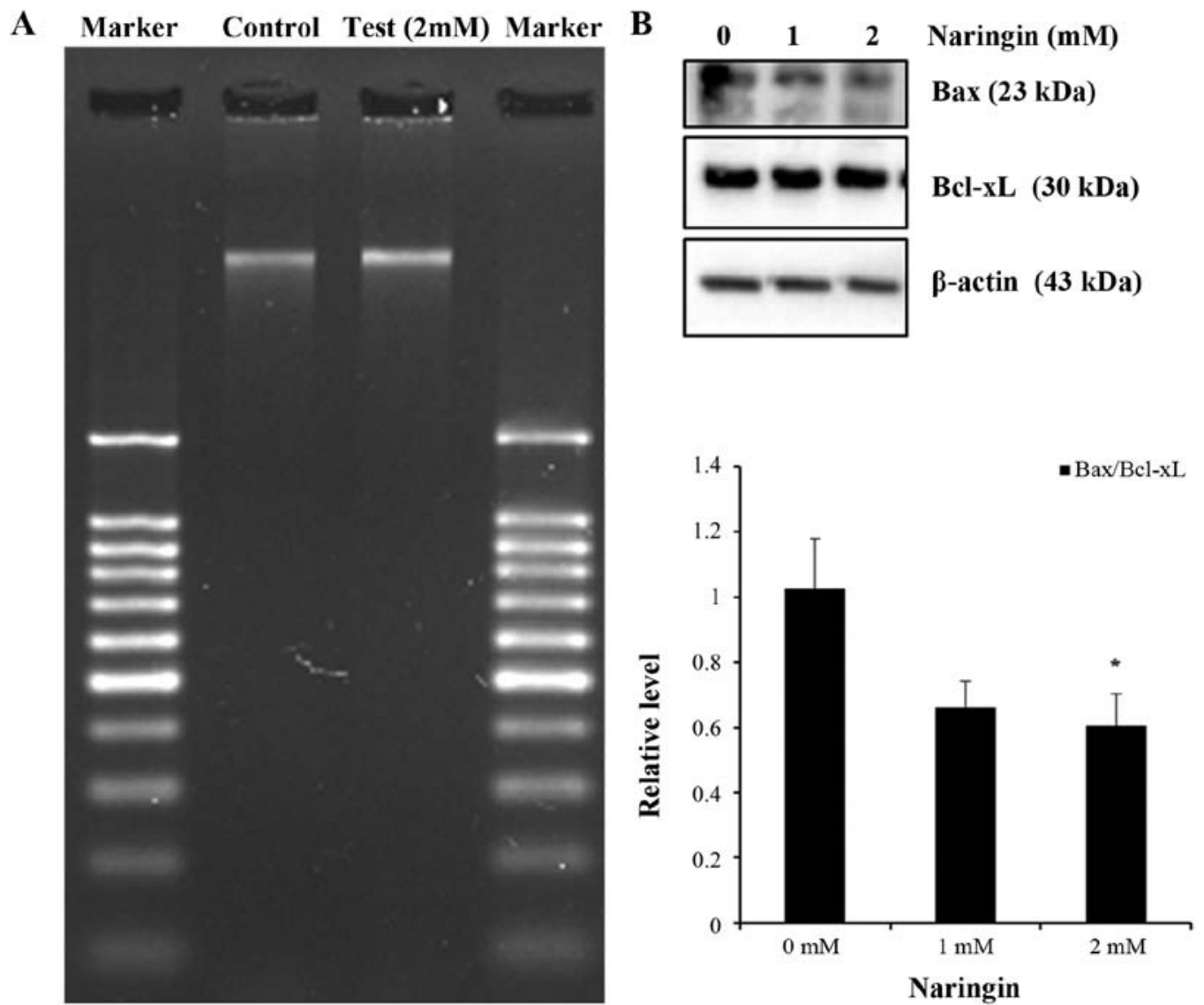

Figure 2. Naringin does not show apoptotic effect on AGS cells. (A) Representative image of DNA fragmentation in untreated and Naringin-treated AGS cells There was no DNA ladder formation in treated group compared with control. (B) Effect of Naringin expression on apoptosis related protein Bax (23 kDa) and $\mathrm{Bcl}-\mathrm{xL}(30 \mathrm{kDa})$ was detected by western blot analysis. Densitometric analyses showed a decreasing trend of Bax/Bcl-xL ratio compared with their relative untreated control cells. Data represent the mean $\pm \mathrm{SD}$ of three replicated independent experiments. ${ }^{*} \mathrm{p}<0.05$ compared with control group.

stimulates cell growth through activation of PI3K. The present experimental results determined that phosphorylation of PI3K and its activated downstream targets p-Akt and p-mTOR are significantly decreased at $2 \mathrm{mM}$ in Naringintreated AGS cells, observed by immunoblot analysis (Fig. 3A). To further validate the effect of Naringin on cell growth inhibition via PI3K pathway, pre-treatment of AGS cells with $10 \mu \mathrm{M}$ of LY294002 as described earlier was done by western blot analysis (Fig. 3B). It was observed that pretreatment with LY294002 inhibited the expression of PI3K in Naringin-treated cells. The above data represent the antiproliferative role of Naringin in AGS cancer cells.

Naringin induces autophagosome. Electron microscopic investigation is still the most reliable method for monitoring autophagic morphology (33). The TEM observation reports revealed formation of double-membrane vesicles containing subcellular materials, representing formation of phagophore in $2 \mathrm{mM}$ Naringin-treated cells when compared with the non-treated AGS cells (Fig. 4) showing the vesicle formation in $2 \mathrm{mM}$ Naringin treated cells with damaged organelles, such as swollen mitochondria/lysosomes surrounded by double-membrane vacuoles, which further formed autophagosomes.

To further elucidate the molecular mechanisms that underlie Naringin-induced autophagosome, examination was done to assess the expression of vacuolar protein Beclin1 and microtubule-associated protein light chain 3 (LC3) in AGS cancer cells. The observed data represented a gradual increase of Beclin 1 protein, including an increased conversion of cytosolic LC3-I protein to autophagic isoform LC3-II (LC3 II/LC3 I ratio) that was significant at $2 \mathrm{mM}$ Naringin-treated AGS cells compared with control (Fig. 5A). In addition to confirming the effect of Naringin on LC3B conversion, examination was done with $10 \mu \mathrm{M}$ of LY294002 pre-treatment. Western blot analysis result (Fig. 5B) revealed that the conversion of LC3B was inhibited in the presence of LY294002. Taken together, these results indicated that Naringin induces autophagy in AGS cancer cells.

Activation of MAPK signaling pathways in Naringin-treated AGS cells. MAPK signaling pathways play an important role in cell growth inhibition and upregulation of autophagic protein followed by autophagy-mediated cell death. To further investigate the role of MAPK family proteins in Naringin-treated AGS cells inducing autophagy, western blot analysis was done. As shown (Fig. 6), Naringin induced significant activation of p-ERK1/2, p-p38 at $2 \mathrm{mM}$ and p-JNK at $1 \mathrm{mM}$ concentration in AGS cells during 24-h incubation. Taken together, these results demonstrated that MAPK signaling pathways are involved in Naringin-induced autophagic cell growth inhibition in AGS cells. 


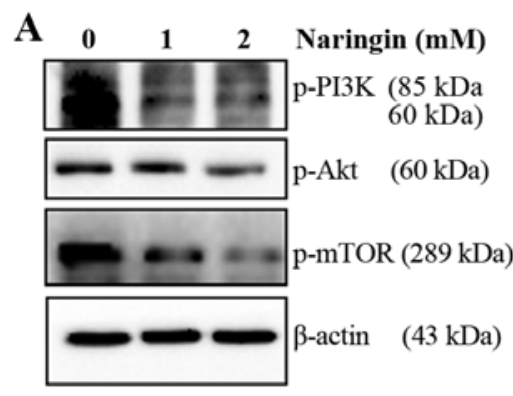

B

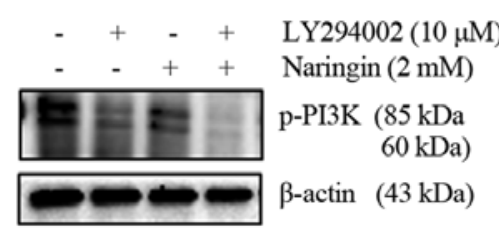

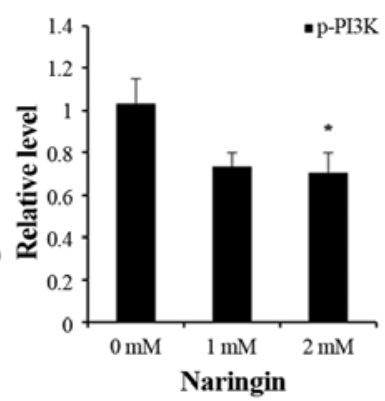
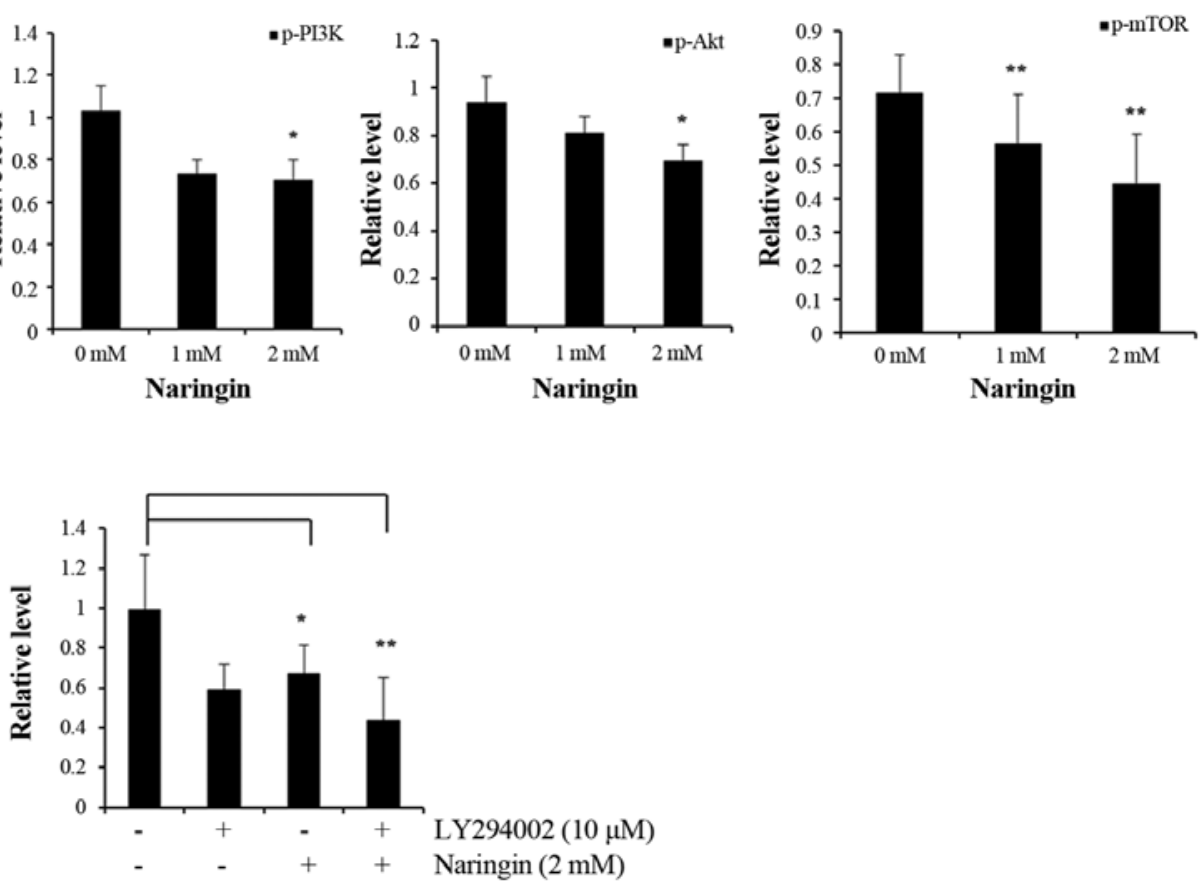

Figure 3. Naringin suppresses the PI3K/Akt/mTOR signaling pathway. (A) AGS cells were treated with Naringin at 1 and $2 \mathrm{mM}$, for $24 \mathrm{~h}$ and immunoblot analysis was performed. Protein expression of p-PI3K (60 and $85 \mathrm{kDa})$, p-Akt $(60 \mathrm{kDa})$ and p-mTOR $(289 \mathrm{kDa})$ were normalized to their respective total protein. $\beta$-actin was used as a loading control. (B) Effect of PI3K inhibitor on Naringin-induced growth inhibition in AGS cells. AGS cells were pretreated with $10 \mu \mathrm{M}$ of PI3K inhibitor: LY294002 for $2 \mathrm{~h}$ prior to $2 \mathrm{mM}$ Naringin treatment. Whole cell lysates were subjected to immunoblotting. Data represent the mean \pm SD of three replicated independent experiments. " $\mathrm{p}<0.05$ and ${ }^{* *} \mathrm{p}<0.01$ compared with the control group.
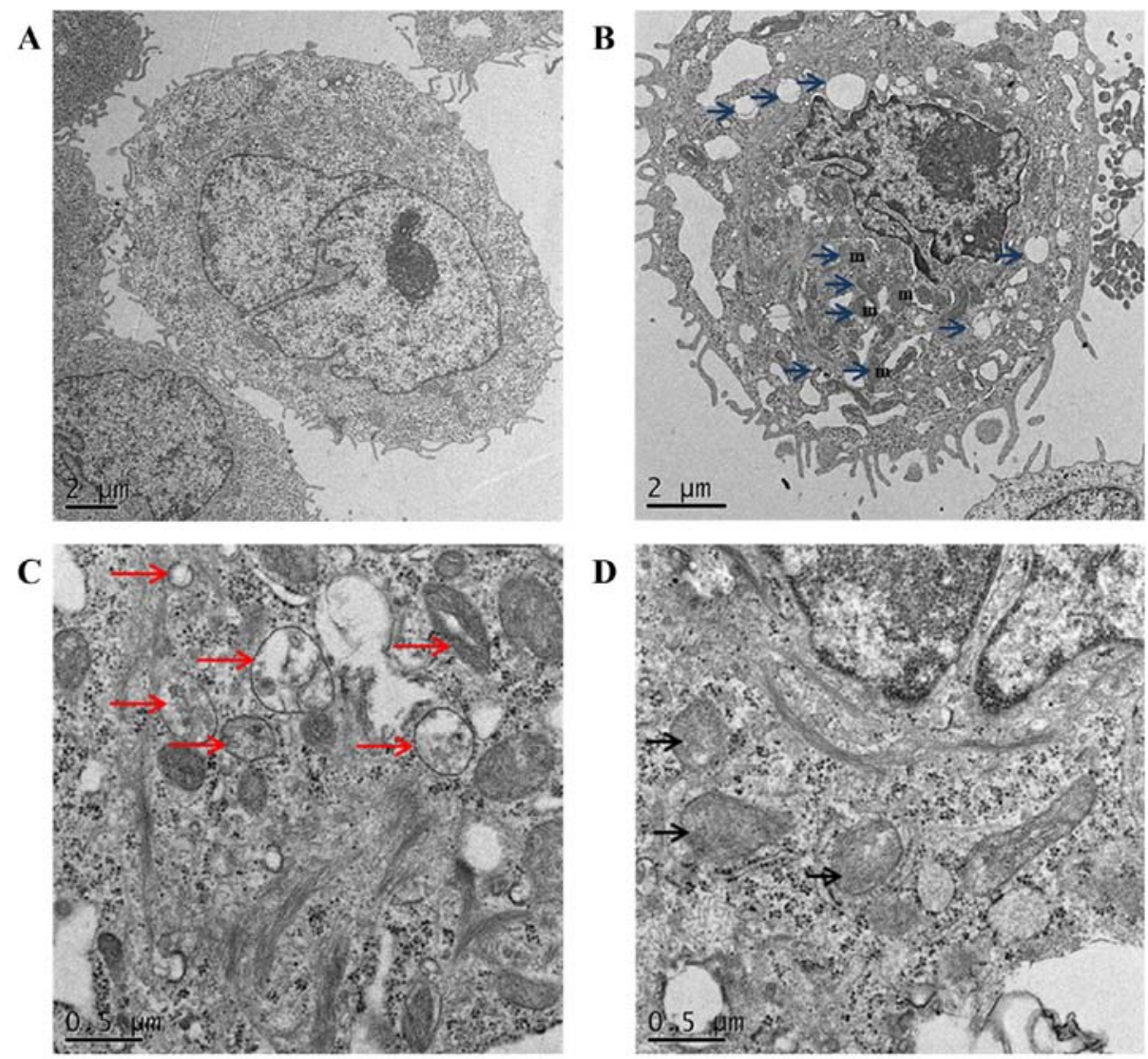

Figure 4. Formation of autophagosome by Naringin-treated AGS cancer cells. Electron microscopy showing the ultrastructure of AGS cells untreated and treated with $2 \mathrm{mM}$ Naringin for $24 \mathrm{~h}$. (A) Control cells with normal cytoplasmic organelle and uncondensed chromatin, (B) Naringin-treated cells showing increased number of cytoplasmic vacuoles and swollen mitochondria, (C) Naringin induced damaged cellular organelles with double-membrane autophagosomes and (D) formation of swollen lysosome were observed in treated cells. Blue arrows indicate cytoplasmic vacuolization and swollen mitochondria, red arrows for autophagosomes and black arrow for swollen lysosomes. 
A

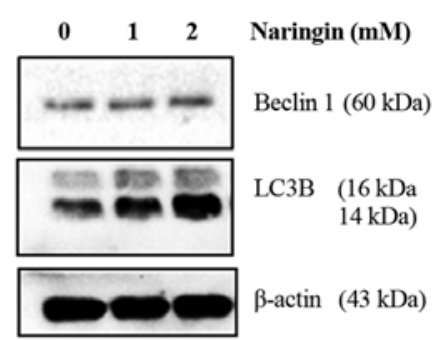

B

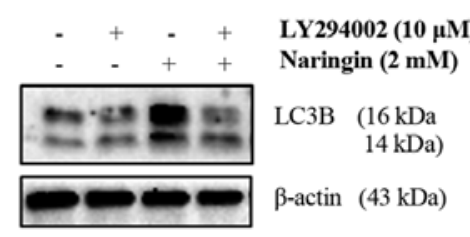

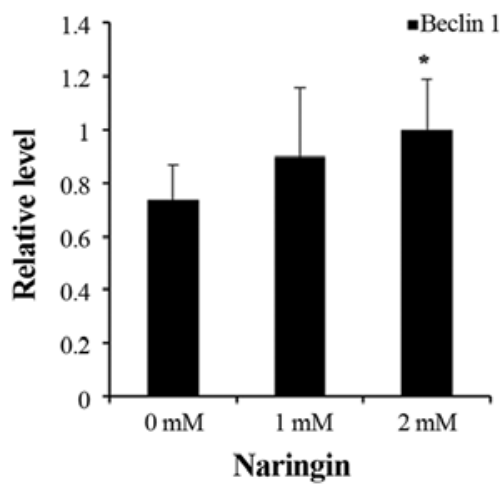

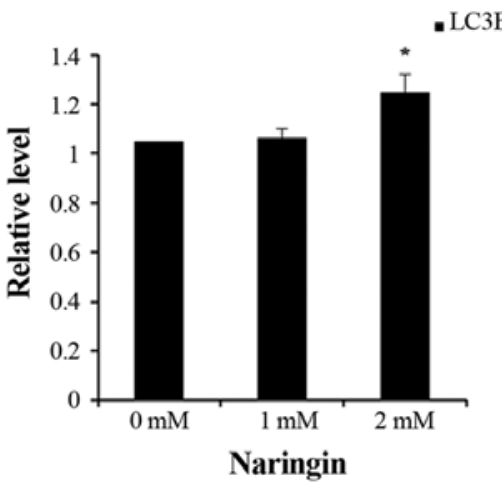

Figure 5. Naringin induces autophagic cell death in AGS cells. Naringin activated the autophagy related protein in AGS cells. (A) After 24-h incubation with 1 and $2 \mathrm{mM}$ of Naringin in AGS cells, Beclin $1(60 \mathrm{kDa})$ and LC3B (14 and $16 \mathrm{kDa})$ protein expression was determined by western blotting. (B) Cells were pre-treated with $10 \mu \mathrm{M}$ of LY294002 (LC3B blocker) for $2 \mathrm{~h}$ prior to $2 \mathrm{mM}$ Naringin treatment for $24 \mathrm{~h}$ and LC3B conversion was determined by western blotting. Quantitative data represent the means \pm SD of three replicated independent experiments. * $p<0.05$ and ${ }^{* *} \mathrm{p}<0.01$ compared with control group.
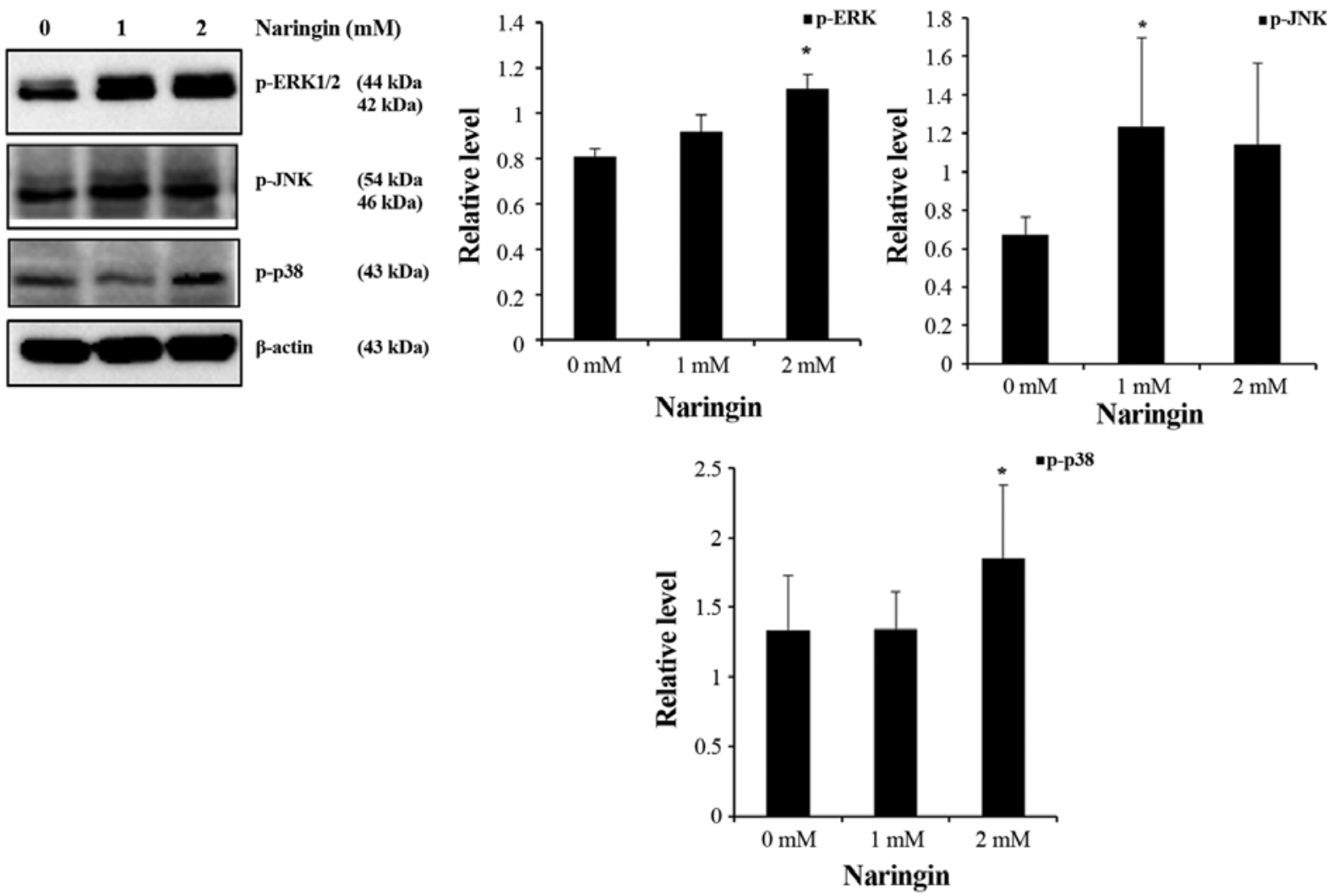

Figure 6. Activation of MAPKs in Naringin-treated AGS cells. For representative immunoblot analysis of p-ERK1/2 (42 and 44 kDa), p-JNK (46 and 54 kDa), p-p38 (43 kDa) protein expression, AGS cells were treated with indicated concentrations of Naringin for $24 \mathrm{~h}$. For phosphorylated MAPKs, protein levels were normalized to their respective total MAPKs. $\beta$-actin was used as a loading control. Data represent the mean \pm SD of three replicated independent experiments. " $\mathrm{p}<0.05$ compared with the control group. 

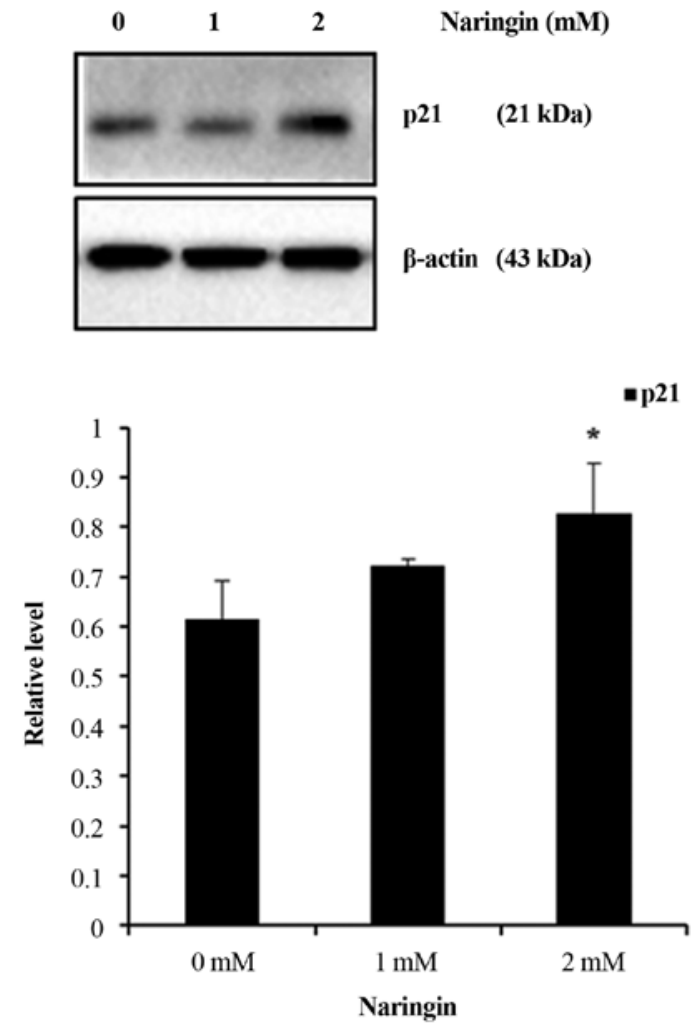

Figure 7. Naringin upregulates p21 in AGS cells. The activation of p21 in $2 \mathrm{mM}$ Naringin-treated AGS cells for $24 \mathrm{~h}$ was determined by western blotting. Densitometric analysis of upregulated p21/ $\beta$-actin is presented. Data represent the mean \pm SD of three replicated independent experiments. * $\mathrm{p}<0.05$ compared with control group.

Upregulation of 21 plays a role in AGS cell anti-proliferation. A marked overexpression of $\mathrm{p} 21^{\mathrm{WAF} 1 / \mathrm{CIP} 1}$ in Naringin-treated cancer cells inducing apoptotic cell death in breast cancer and cell cycle arrest in bladder cell carcinoma have been reported $(34,35)$. To further assess the cell anti-proliferative mechanism by $\mathrm{p} 21^{\mathrm{WAF} 1 / \mathrm{CIP} 1}$ protein, expression study was determined by immunoblot analysis. The result demonstrated a significant increase of $\mathrm{p} 21^{\mathrm{WAF} 1 / \mathrm{CIP} 1}$ expression at $2 \mathrm{mM}$ in Naringin-treated AGS cells (Fig. 7). The observed data could be correlated with the induction of autophagy depicting the role of p21 in Naringin-inducing cell death in AGS cancer cells.

\section{Discussion}

The study of plant flavonoids as anticancer agents has increased substantially, due in part to their profound effects in cell death signaling pathways $(36,37)$. Flavonoids are a group of polyphenolic secondary metabolites with diphenyl propane (C6C3C6) skeletons. Major classes of flavonoids are anthocyanins, flavonols, flavanols and proanthocyanidins or condensed tannins (38). Naringin, as one of the most abundant flavonoids in citrus containing anaglycone moiety named naringenin, linked to a dioside neohesperidoside (39). It has been implicated for its pharmacological values based on recent reports on its ability to inhibit cell growth in breast cancer cells through $\beta$-catenin pathway (34) or as anti-oxidant in mouse leukemia P388 cells (40). In addition, activation of Ras/Raf/ERK inducing G1-cell cycle arrest via p $21^{\mathrm{WAF} 1}$ has been observed in Naringin-treated bladder carcinoma cells (35) or induction of apoptosis through both death receptor and mitochondrial pathway in cervical cancer ( $\mathrm{SiHa}$ ) cells (41). Herein, the present study revealed that Naringin inhibited cell proliferation dose- and timedependently with an opted EC value of $2 \mathrm{mM}$ at $24 \mathrm{~h}$ inducing autophagy in human AGS cells, which suggested Naringin possesses a potential anti-proliferative effect on AGS cancer cells.

Bcl-2 family has been reported as the best characterized protein family, playing an important role in regulation of apoptotic cell death (42). Previous reports of Naringin showed induction of apoptosis in human cervical cancer cells, breast cancer cells and mouse leukemia P388 cells $(34,40,41)$. In the present study, Naringin-treated AGS cells presented no DNA fragmentation with a decreasing expression of pro-apoptotic protein Bax and anti-apoptotic proteins Bcl-xL ratio. Similar reports $(11,13)$ on non-apoptotic cell death confirmed that the effect of Naringin did not trigger apoptotic pathway in AGS cells.

$\mathrm{PI} 3 \mathrm{~K} / \mathrm{Akt} / \mathrm{mTOR}$ cascades are the most frequently deregulated and inappropriately activated cancer signaling pathway, controlling cellular energy, cell growth, proliferation, senescence and angiogenesis in cancer cells. Blocking different nodes of this pathway is a relevant treatment strategy for human malignancies (8). Several bioactive components such as samsoeum (17), polyphenols of Korean Lonicera japonica (43), araguspongine C (44), justicidin A (45), flavonoids including luteolin (46), baicalein (47) possess anticancer activity by suppressing PI3K/Akt/mTOR pathway in cancer cells. To date, mTOR is the most well characterized negative regulator of autophagy in cancer cells suggesting that decrease of autophagic activity is related to tumorigenesis (8). Similarly, the present study showed the potential involvement of PI3K/Akt/mTOR signaling pathway in Naringin-treated AGS cells, further confirmed by the PI3K specific inhibitor LY294002.

Induction of autophagy in Naringin-treated AGS cells evidencing the accumulation of biochemical hallmark proteins of autophagy, Beclin 1 and LC3-II, known to play pivotal roles in the formation of autophagosomes. The mammalian autophagy gene Beclin 1, as part of the PI3K complexes, participates in the formation of autophagic vesicles and localizing autophagic proteins (48). Elevation of Beclin 1 and the conversion of LC3-I to LC3-II correlates with the extent of autophagosome formation, indicating LC3-II as the most widely used biomarker of autophagosomes formation in tumor suppressor mechanism (10). Similarly, the present finding supports Beclin1 and LC3-II activation in a dose-dependent manner, as evidenced by immunoblotting. In addition, the conserved positive role of Class III PI3K in the autophagic process, 3-MA as a PI3K inhibitor, has been reported as a specific autophagy inhibitor of the conversion of LC3 expression (49). Similarly, the present study also suggested that PI3K inhibitor LY294002, which blocked the LC3B conversion, confirms that Naringin induces autophagic cell death in AGS cancer cells.

MAPK kinases play an integral role in the inception and execution of autophagy. It leads to phosphorylation-dependent activation of other kinases and transcription factors. The beststudied MAP kinases are ERK, p38 and JNK. While ERK is activated in response to proliferative signals, p38 and JNK 
are activated in response to various stresses (19). Activation of ERK1/2 during growth inhibition and apoptosis have been observed in cancer cells $(18,35)$, while activation of JNK is required for the upregulation of Beclin 1 triggering autophagymediated cell death $(14,17)$. Subsequently, p38 MAPK activation has been addressed during autophagic cell death (50). Therefore, the observed result indicated that Naringin-induced autophagy in AGS cells is associated with the activation of MAPK signaling pathways.

p21 gene has been widely studied as an antitumor gene, regulated directly by $\mathrm{p} 53$ gene. In addition, $\mathrm{p} 21$ can bind to proliferating cell nuclear antigen (PCNA) thereby blocking DNA synthesis (51). It has been reported (22) that increased expression of $\mathrm{p} 21^{\mathrm{CIPI} / \mathrm{WAFI}}$ by Clozapine-treated lung cancer cells in a time-dependent manner simultaneously increase the number of autophagosomes, which correlate with the present study on anti-proliferative effect of Naringin-inducing autophagosome in AGS cancer cells.

The present findings clearly demonstrate that antiproliferative activity of Naringin-treated human AGS cancer cells leads to induction of autophagy by suppressing PI3K/ Akt/mTOR signaling pathway through activation of MAPKs. Further study will be undertaken to explore the molecular mechanism of autophagy-related growth inhibition and anticancer activities of Naringin-treated AGS cancer cells. Therefore, induction of autophagy or autophagic cell death by bioactive flavonoid Naringin would play an important role as an anticancer therapeutic agent enhancing the treatment responses for human gastric carcinoma.

\section{Acknowledgements}

This study was supported by a grant from the National Research Foundation (NRF) of Korea funded by the Ministry of Science (no. 2012M3A9B8019303), ICT \& Future Planning (no. 2012R1A2A2A06045015) and National R\&D Program for Cancer Control, Ministry for Health, Welfare and Family Affairs, Republic of Korea (no. 0820050).

\section{References}

1. McLean MH and El-Omar EM: Genetics of gastric cancer. Nat Rev Gastroenterol Hepatol 11: 664-674, 2014.

2. World Health Organization. GLOBOCAN 2012: Estimated cancer incidence, mortality and prevalence worldwide in 2012 Available online: http://globocan.iarc.fr.

3. Torre LA, Bray F, Siegel RL, Ferlay J, Lortet-Tieulent J and Jemal A: Global cancer statistics, 2012. CA Cancer J Clin 65: 87-108, 2015.

4. Ferlay J, Soerjomataram I, Dikshit R, Eser S, Mathers C, Rebelo M, Parkin DM, Forman D and Bray F: Cancer incidence and mortality worldwide: Sources, methods and major patterns in GLOBOCAN 2012. Int J Cancer 136: E359-E386, 2015.

5. Nagini S: Carcinoma of the stomach: A review of epidemiology, pathogenesis, molecular genetics and chemoprevention. World J Gastrointest Oncol 4: 156-169, 2012.

6. Hanahan D and Weinberg RA: Hallmarks of cancer: The next generation. Cell 144: 646-674, 2011.

7. Shaw RJ and Cantley LC: Ras, PI(3)K and mTOR signalling controls tumour cell growth. Nature 441: 424-430, 2006.

8. Xie X, White EP and Mehnert JM: Coordinate autophagy and mTOR pathway inhibition enhances cell death in melanoma. PLoS One 8: e55096, 2013

9. Meijer AJ and Codogno P: Regulation and role of autophagy in mammalian cells. Int J Biochem Cell Biol 36: 2445-2462, 2004.

10. Gozuacik D and Kimchi A: Autophagy as a cell death and tumor suppressor mechanism. Oncogene 23: 2891-2906, 2004.
11. De A, De A, Papasian C, Hentges S, Banerjee S, Haque I and Banerjee SK: Emblica officinalis extract induces autophagy and inhibits human ovarian cancer cell proliferation, angiogenesis, growth of mouse xenograft tumors. PLoS One 8: e72748, 2013.

12. Law BY, Chan WK, Xu SW, Wang JR, Bai LP, Liu L and Wong VK: Natural small-molecule enhancers of autophagy induce autophagic cell death in apoptosis-defective cells. Sci Rep 4: 5510, 2014.

13. Hao W, Zhang X, Zhao W and Chen X: Psoralidin induces autophagy through ROS generation which inhibits the proliferation of human lung cancer A549 cells. Peer J 2: e555, 2014.

14. Xie CM, Chan WY, Yu S, Zhao J and Cheng CH: Bufalin induces autophagy-mediated cell death in human colon cancer cells through reactive oxygen species generation and JNK activation. Free Radic Biol Med 51: 1365-1375, 2011.

15. Chen YJ, Chi CW, Su WC and Huang HL: Lapatinib induces autophagic cell death and inhibits growth of human hepatocellular carcinoma. Oncotarget 5: 4845-4854, 2014.

16. Seger R and Krebs EG: The MAPK signaling cascade. FASEB J 9: 726-735, 1995

17. Kim A, Yim NH and Ma JY: Samsoeum, a traditional herbal medicine, elicits apoptotic and autophagic cell death by inhibiting akt/mTOR and activating the JNK pathway in cancer cells. BMC Complement Altern Med 13: 233,6882-13-233, 2013.

18. Lee JW, Kim KS, An HK, Kim CH, Moon HI and Lee YC: Dendropanoxide induces autophagy through ERK1/2 activation in MG-63 human osteosarcoma cells and autophagy inhibition enhances dendropanoxide-induced apoptosis. PLoS One 8: e83611, 2013.

19. Sridharan S, Jain K and Basu A: Regulation of autophagy by kinases. Cancers (Basel) 3: 2630-2654, 2011.

20. Capparelli C, Chiavarina B, Whitaker-Menezes D, Pestell TG, Pestell RG, Hulit J, Andò S, Howell A, Martinez-Outschoorn UE, Sotgia F, et al: CDK inhibitors (p16/p19/p21) induce senescence and autophagy in cancer-associated fibroblasts, 'fueling' tumor growth via paracrine interactions, without an increase in neoangiogenesis. Cell Cycle 11: 3599-3610, 2012.

21. Abbas T and Dutta A: p21 in cancer: Intricate networks and multiple activities. Nat Rev Cancer 9: 400-414, 2009.

22. Yin YC, Lin CC, Chen TT, Chen JY, Tsai HJ, Wang CY and Chen SY: Clozapine induces autophagic cell death in non-small cell lung cancer cells. Cell Physiol Biochem 35: 945-956, 2015.

23. Ekor M: The growing use of herbal medicines: Issues relating to adverse reactions and challenges in monitoring safety. Front Pharmacol 4: 177, 2014.

24. Park KI, Park HS, Nagappan A, Hong GE, Lee H, Kang SR, Kim JA, Zhang J, Kim EH, Lee WS, et al: Induction of the cell cycle arrest and apoptosis by flavonoids isolated from Korean Citrus aurantium L. in non-small-cell lung cancer cells. Food Chem 135: 2728-2735, 2012.

25. Delle Monache S, Sanità $\mathrm{P}$, Trapasso E, Ursino MR, Dugo P, Russo M, Ferlazzo N, Calapai G, Angelucci A and Navarra M: Mechanisms underlying the anti-tumoral effects of Citrus Bergamia juice. PLoS One 8: e61484, 2013.

26. Camargo CA, Gomes-Marcondes MC, Wutzki NC and Aoyama H: Naringin inhibits tumor growth and reduces interleukin- 6 and tumor necrosis factor $\alpha$ levels in rats with Walker 256 carcinosarcoma. Anticancer Res 32: 129-133, 2012.

27. Kumar A, Prakash A and Dogra S: Naringin alleviates cognitive impairment, mitochondrial dysfunction and oxidative stress induced by D-galactose in mice. Food Chem Toxicol 48: 626-632, 2010.

28. Lee EJ, Kim DI, Kim WJ and Moon SK: Naringin inhibits matrix metalloproteinase-9 expression and AKT phosphorylation in tumor necrosis factor-alpha-induced vascular smooth muscle cells. Mol Nutr Food Res 53: 1582-1591, 2009.

29. Nie YC, Wu H, Li PB, Luo YL, Long K, Xie LM, Shen JG and Su WW: Anti-inflammatory effects of naringin in chronic pulmonary neutrophilic inflammation in cigarette smokeexposed rats. J Med Food 15: 894-900, 2012.

30. Kanno S, Tomizawa A, Hiura T, Osanai Y, Shouji A, Ujibe M, Ohtake T, Kimura K and Ishikawa M: Inhibitory effects of naringenin on tumor growth in human cancer cell lines and sarcoma S-180-implanted mice. Biol Pharm Bull 28: 527-530, 2005.

31. Zeng L, Zhen Y, Chen Y, Zou L, Zhang Y, Hu F, Feng J, Shen J and Wei B: Naringin inhibits growth and induces apoptosis by a mechanism dependent on reduced activation of NF- $\kappa \mathrm{B} / \mathrm{COX}$-2-caspase-1 pathway in HeLa cervical cancer cells. Int J Oncol 45: 1929-1936, 2014.

32. Rogakou EP, Nieves-Neira W, Boon C, Pommier Y and Bonner WM: Initiation of DNA fragmentation during apoptosis induces phosphorylation of H2AX histone at serine 139. J Biol Chem 275: 9390-9395, 2000. 
33. Mizushima N: Methods for monitoring autophagy. Int J Biochem Cell Biol 36: 2491-2502, 2004.

34. Li H, Yang B, Huang J, Xiang T, Yin X, Wan J, Luo F, Zhang L, Li H and Ren G: Naringin inhibits growth potential of human triple-negative breast cancer cells by targeting $\beta$-catenin signaling pathway. Toxicol Lett 220: 219-228, 2013.

35. Kim DI, Lee SJ, Lee SB, Park K, Kim WJ and Moon SK Requirement for Ras/Raf/ERK pathway in naringin-induced G1-cell-cycle arrest via p21WAF1 expression. Carcinogenesis 29: 1701-1709, 2008.

36. Shi MD, Liao YC, Shih YW and Tsai LY: Nobiletin attenuates metastasis via both ERK and PI3K/Akt pathways in HGF-treated liver cancer HepG2 cells. Phytomedicine 20: 743-752, 2013.

37. Yumnam S, Park HS, Kim MK, Nagappan A, Hong GE, Lee HJ, Lee WS, Kim EH, Cho JH, Shin SC, et al: Hesperidin induces paraptosis like cell death in hepatoblatoma, HepG2 cells: Involvement of ERK1/2 MAPK. PLoS One 9: e101321, 2014.

38. Chahar MK, Sharma N, Dobhal MP and Joshi YC: Flavonoids: A versatile source of anticancer drugs. Pharmacogn Rev 5: 1-12, 2011.

39. Fuhr U and Kummert AL: The fate of naringin in humans: A key to grapefruit juice-drug interactions? Clin Pharmacol Ther 58: 365-373, 1995

40. Kanno S, Shouji A, Asou K and Ishikawa M: Effects of naringin on hydrogen peroxide-induced cytotoxicity and apoptosis in P388 cells. J Pharmacol Sci 92: 166-170, 2003.

41. Ramesh E and Alshatwi AA: Naringin induces death receptor and mitochondria-mediated apoptosis in human cervical cancer (SiHa) cells. Food Chem Toxicol 51: 97-105, 2013

42. Asnaghi L, Calastretti A, Bevilacqua A, D'Agnano I, Gatti G, Canti G, Delia D, Capaccioli S and Nicolin A: Bcl-2 phosphorylation and apoptosis activated by damaged microtubules require mTOR and are regulated by Akt. Oncogene 23: 5781-5791, 2004.

43. Park HS, Park KI, Lee DH, Kang SR, Nagappan A, Kim JA, Kim EH, Lee WS, Shin SC, Hah YS, et al: Polyphenolic extract isolated from Korean Lonicera japonica Thunb. induce G2/M cell cycle arrest and apoptosis in HepG2 cells: Involvements of PI3K/Akt and MAPKs. Food Chem Toxicol 50: 2407-2416, 2012.
44. Akl MR, Ayoub NM, Ebrahim HY, Mohyeldin MM, Orabi KY, Foudah AI and El Sayed KA: Araguspongine C induces autophagic death in breast cancer cells through suppression of c-Met and HER2 receptor tyrosine kinase signaling. Mar Drugs 13: 288-311, 2015.

45. Won SJ, Yen CH, Liu HS, Wu SY, Lan SH, Jiang-Shieh YF, Lin CN and Su CL: Justicidin A-induced autophagy flux enhances apoptosis of human colorectal cancer cells via class III PI3K and Atg5 pathway. J Cell Physiol 230: 930-946, 2015.

46. Lee WJ, Wu LF, Chen WK, Wang CJ and Tseng TH: Inhibitory effect of luteolin on hepatocyte growth factor/scatter factorinduced HepG2 cell invasion involving both MAPK/ERKs and PI3K-Akt pathways. Chem Biol Interact 160: 123-133, 2006.

47. Aryal P, Kim K, Park PH, Ham S, Cho J and Song K: Baicalein induces autophagic cell death through AMPK/ULK1 activation and downregulation of mTORC1 complex components in human cancer cells. FEBS J 281: 4644-4658, 2014.

48. Kang R, Zeh HJ, Lotze MT and Tang D: The Beclin 1 network regulates autophagy and apoptosis. Cell Death Differ 18: 571-580, 2011.

49. Li X, Li X, Wang J, Ye Z and Li JC: Oridonin up-regulates expression of P21 and induces autophagy and apoptosis in human prostate cancer cells. Int J Biol Sci 8: 901-912, 2012.

50. Cui Q, Tashiro S, Onodera S, Minami M and Ikejima T: Oridonin induced autophagy in human cervical carcinoma HeLa cells through Ras, JNK, and P38 regulation. J Pharmacol Sci 105: 317-325, 2007.

51. Mohapatra P, Preet R, Das D, Satapathy SR, Choudhuri T, Wyatt MD and Kundu CN: Quinacrine-mediated autophagy and apoptosis in colon cancer cells is through a p53- and p21-dependent mechanism. Oncol Res 20: 81-91, 2012. 